\title{
Aluminum Nanocomposites Reinforced with Carbon Nanotubes - A Research
}

\author{
Udaya, Sunil kumar Shetty, Peter Fernandes
}

\begin{abstract}
This paper basically surveys the continuing development in metal framework composites bolstered with carbon nanotubes (CNTs). Aluminum metal framework composites fortified with CNTs have become extra significance because of their low thickness, remarkable mechanical and tribological homes. CNT bolstered Al steel lattice composites commonly preferred composites in easy applications. it's miles clean from the writing that no matter the truth that extra extension for the nanocomposites exists however troubles in handling upsets the improvement in Al/CNT composites. This audit paper illuminates part of the handling strategies with the purpose that future investigates might also moreover spark off first rate results inside the manufacture of awesome composite materials.
\end{abstract}

Report terms: Carbon nanotubes, metal framework composites,, Powder metallurgy, Scanning electron magnifying lens

\section{PRESENTATION}

The deficiency of strong substances for giving high concord to weight percentage houses to the primary applications made the development of steel framework composites (MMCs). In MMCs extraordinary and malleability is accomplished by way of using the increase of fortification which is each fired or metal itself as fiber or particulate. MMCs are extensively carried out in motors and avionic business employer due to their notable mechanical and wear residences. The creation of carbon nanotubes (CNTs) drove the route for investigate in nanoscale fortifications in composites to develop terrific composites as a long way as warm temperature, mechanical or maybe electric houses. diverse explores disbursed on the polymer primarily based definitely composites in a decade in the past due to their simplicity of making ready which want no longer problem with excessive temperature scenario that required for fired or grid materials as regarded in Fig 1. because of their weak issue earthenware manufacturing have not been implemented in numerous auxiliary applications. increase of CNTs can be required to defeat the issue of fragility. most potential of carbon nanotubes has now not been said in pottery and metals which request a functioning go searching there. The immoderate temperature condition in normal getting prepared of MMCs damage the carbon nanotubes and moreover need of manipulate of interface most of the

Revised Version Manuscript Received on 10, September 2019.

Udaya, Mechanical Engineering Department, NMAM Institute of Technology, Nitte, Karkala, Karnataka, India.(E-mail: udaya140213@gmail.com)

Sunil Kumar shetty , Mechanical Engineering, Department, NMAM Institute of Technology, Nitte, Karkala, Karnataka, India. (E-mail: sunilkumarshetty@nitte.edu.in)

Dr. Peter Fernandes, Principal, Alva's Institute of Engineering \& Technology, Moodbidri, Karnataka India.(E-mail: petfdcm@gmail.com) community and fortifications is easy for superior homes. This paper audits a portion of the improvements inside the CNT fortified MMCs to have mastering on the CNTs, its preparing approaches and moreover to middle the future studies scope on this location.

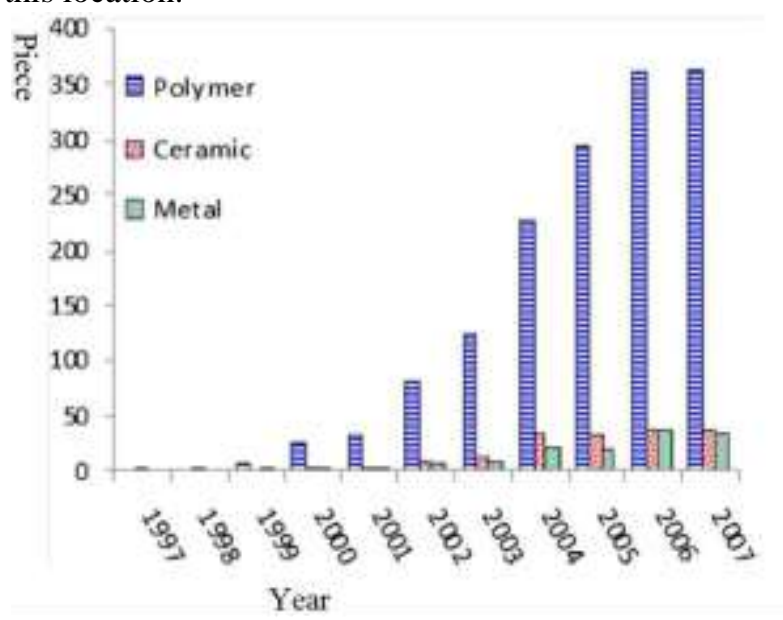

Figure 1 statics of CNT composites reinforced materials.

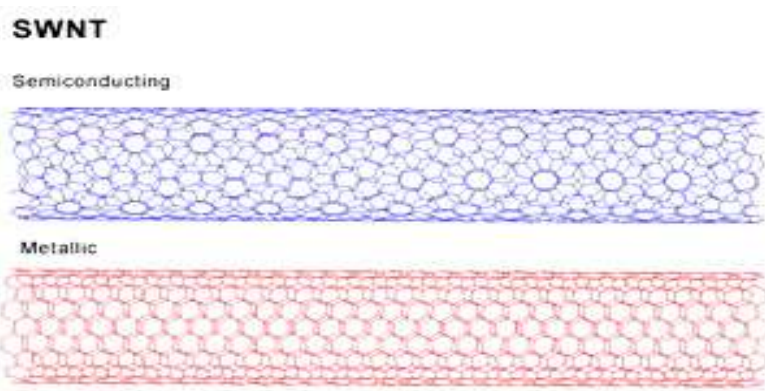

Figure 2 Single walled carbon nanotubes

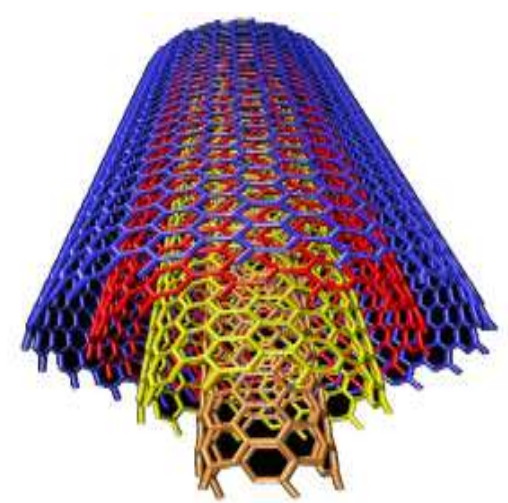

Figure 3 Multi walled carbon nanotubes

Published By:

Blue Eyes Intelligence Engineering

\& Sciences Publication 
CNTs can be viewed as a graphene sheet that has been folded into a cylinder with hemispherical tops at the two finishes. Fig. 2 and 3 demonstrates the two characterization of CNTs, single walled carbon nanotubes(SWCNTs) and multi walled carbon nanotubes (SWCNTs). A multiwalled carbon nanotube (MWCNT) is framed from numerous SWCNTs masterminded in a concentric way. From the test results it has been demonstrated that CNTs have properties of firmness up to $1000 \mathrm{GPa}$, quality of the request for $100 \mathrm{GPa}$ and warm conductivity of up to $6000 \mathrm{~W} / \mathrm{m} \mathrm{K}$ contrasted with carbon strands

\section{CARBON NANOTUBES STRENGTHENED COMPOSITES \& RESULTS}

Senthil saravanan et al.[1] utilized powder metallurgy to manufacture cnt bolstered steel network composites. Figure 4 demonstrates the high dreams transmission electron microscopy picture of multi walled carbon nanotubes. Author implemented excessive vitality ball manufacturing facility to mix mwcnts in aa 4032 amalgam. They were given nanocrystalline form for 30 hours of processing grid powders. They blanketed mwcnts in the direction of the finish of 29 th hour. From the smaller scale auxiliary examination they determined that nearness of cnts within the network and properly scattering of the cnts as appeared in the fig. 5 .

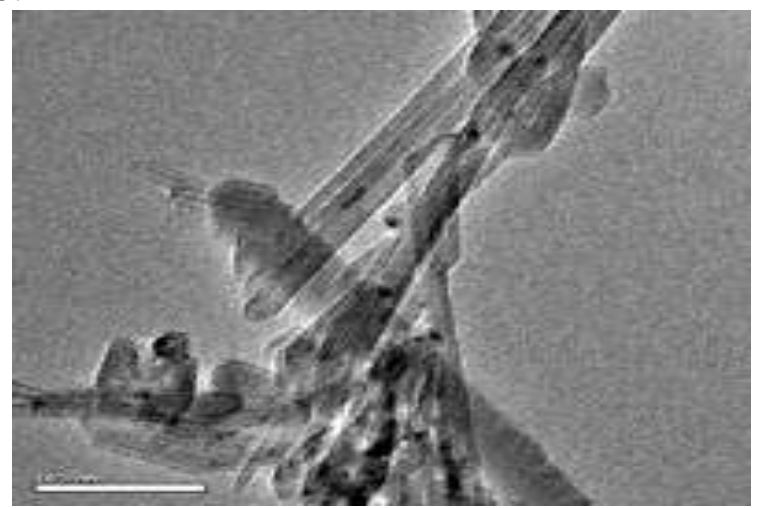

Figure 4 HRTEM image of MWNTs

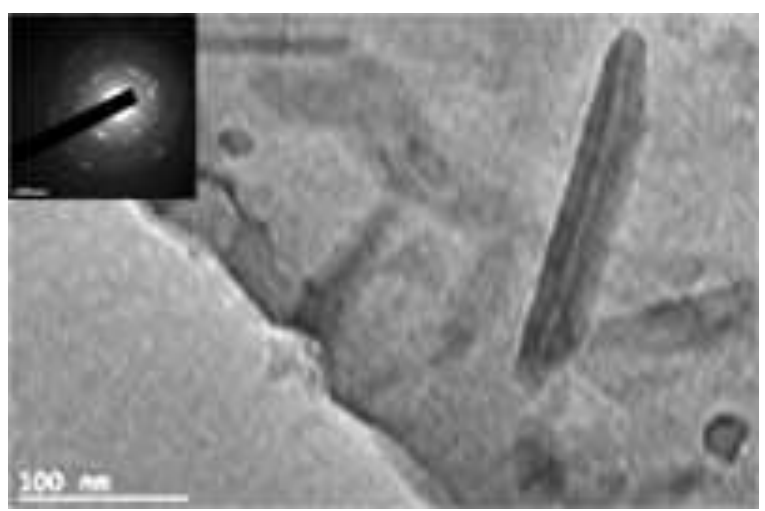

Parent 5 TEM picture of AA 4032/CNT composite powders ( diffraction design inner).[1]

Pérez-Bustamante et al. [2] applied 99.Nine\% unadulterated $\mathrm{Al}$ powder and MWCNTs to manufacture Al-primarily based Nano-composites. The Nano-composites having MWCNTs in zero.25, 0.50 and zero.75wt.\%. The aggregate turned into combined for five min in a ultrasonic shower and precisely processed the usage of high-electricity shaker plant (SPEX-8000M) at diverse processing timings in the nearness Argon fuel. The examples had been installation by using the use of uniaxial burden squeezing in some unspecified time in the future of at $950 \mathrm{MPa}$ for 2 mins. Compacted checks have been then sintered in some unspecified time in the future of $3 \mathrm{~h}$ at $823 \mathrm{~K}$ in vacuum. Microstructural have been watched making use of by means of transmission electron microscopy (TEM).

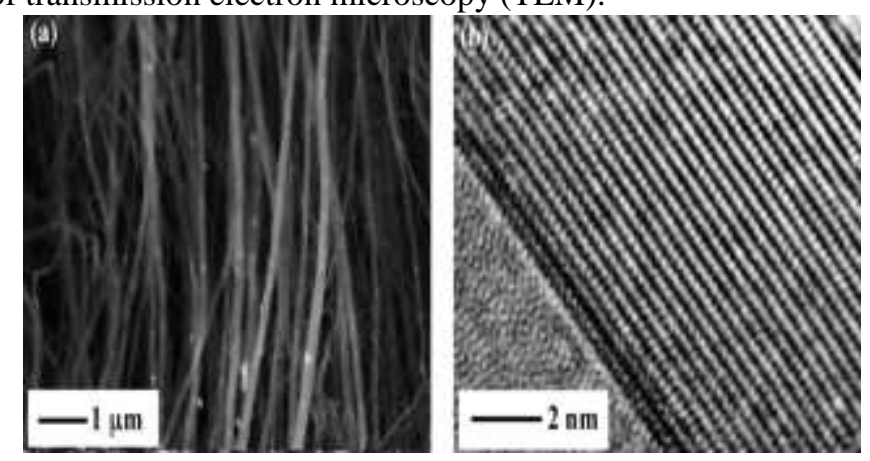

Figure 6(a) SEM photo of MWCNT bundle. (b) TEM photo of a MWCNT. Showing MWCNT walls around $\sim 30$ [2].

Author found that multi walled carbon nanotubes increases the hardness and was $77 \mathrm{HV}$ for the 0.75 wt.\% multi walled carbon nanotubes reinforced composites with 2 hour ball milling. Author concluded that for the lower duration of milling strengthening was due to nanocrystalline state of the materials and longer milling time $(1 \mathrm{~h})$ the most important strengthening effect was due to reinforcements.
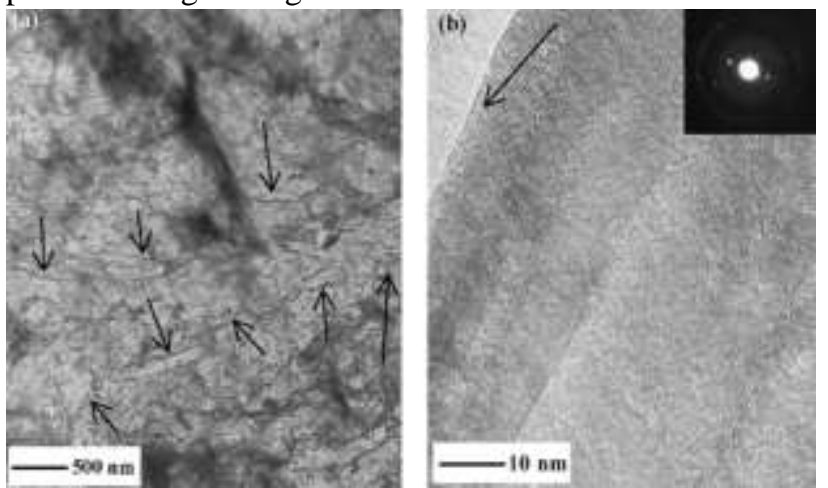

Figure 7. (a) TEM photograph of composite (b) TEM picture of the composite pattern displaying the MWCNT and $\mathrm{Al}$ matrix interface; (diffraction sample interior).

Samuel Ratna Kumar et al. [3] used compo-casting method to broaden composites of uniformly combined multi wall carbon nanotubes reinforcement $(1,1.25,1.50$ and 1.75 wt.\%) in $\mathrm{Al}$ alloy (AA5083) via stir casting. The MWCNT come to be pre heated at 773 adequate to restrict oxide formation and degassed with the useful resource of nitrogen for about 3-four min. The Al alloy (AA5083) have become heated at 1173 okay and bought into semi-sturdy u . S . A . And mixed with the preheated MWCNT and stirred at 250-four hundred rpm and after 2 minutes the liquid metal is transferred to a mildew to get the composite sample. Creator placed advanced hardness and corrosion resistance in organized composite samples.

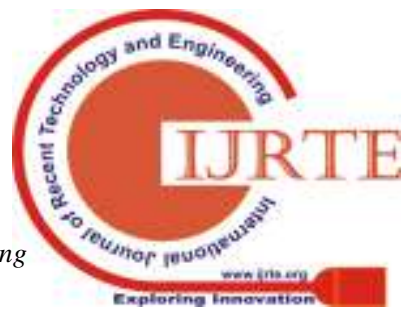


Isaza et al. [4] in this art work, MWCNTs grow to be dispersed in polyvinyl alcohol solution (PVA) (4 wt. \% of PVA in distilled water) and the composite modified into dispersed the use of magnetic stirring method for 1 hour at a median pace of $900 \mathrm{rpm}$ and sonication have turn out to be completed using Vibra mobile series CLC device at amplitude of probe at $20 \%$ and strength of $100 \mathrm{~W}$, power used for dispersion changed into forty five-70kJ. Then the solution became saved for drying to provide reinforced PVA solution. The sheets in which stretched at temperature of eighty ${ }^{\circ} \mathrm{C}$ and at the price of $2 \mathrm{~mm} / \mathrm{min}$. Then the two sheets of PVA/MWCNTs had been stacked as a substitute with sheets of magnesium and warm compacted $\left(580^{\circ} \mathrm{C}\right.$ and forty $\mathrm{MPa}$ ) to evaporate the PVA. In the long run composites had been annealed for $30 \mathrm{~min}$ and heat rolled at $350^{\circ} \mathrm{C}$. Writer found growth in tensile homes, that have turn out to be due to alignment of MWCNTs and proper dispersion that allowed a fantastic load switch. From nano indentation length at the composite showed pretty prolonged mechanical residences which have been because of the presence of MWCNTs.

Chen et al. [5] used the combinations of Al-CNTs powder combined thru using excessive power ball milling (HEBM), solution ball milling (SBM), mechanical coating (MC). The combination were then consolidated with the useful resource of spark plasma sintering (SPS) approach and then heat-extruded. Authors decided that solution ball milling and mechanical coating approach in which preventing CNTs from fracturing and which leads to composites having excessive hassle ratio of CNTs. HEBM strategies reduces CNTs period on the identical time as its milled for long term. It have turn out to be decided that strengthening turn out to be due to the load transfer whilst element ratio of CNTs modified into over 40, after lowering element ratio to a extremely good deal a great deal much less than 10 strengthening mechanism changed to Orowan mechanism.

Kim et al. [6] investigated carbon nanotubes and $\mathrm{TiC}$ nanoparticles reinforced Aluminium metal matrix composites produced the usage of ball-milling and sheath-rolling strategies. Inside the matrix $\mathrm{TiC}$ nanoparticles distribution modified into extensively more through inclusive of a small amount of CNTs (zero.7 vol.\%) in TiC nanoparticles hybridization, and to enhance dispersion of nanoparticles in steel-matrix composites CNTs may be used.

Kwon et al. [7] investigated multi-walled carbon nanotubes (CNT) and Nanodiamond (nD) to beautify natural aluminum (Al) matrix composites. The steel matrix grow to be fabricated using mechanical milling and warmth-pressing. Herbal $\mathrm{Al}$ and $\mathrm{nD}$ or CNT nanoparticle bolstered samples had been moreover produced for contrast cause. Author positioned that micro-Vickers hardness for twin (combination of $\mathrm{nD}$ and $\mathrm{CNT}$ ) nanoparticle-strengthened $\mathrm{Al}$ matrix composites have come to be $127 \mathrm{HV}$ which modified into nearly 5 instances higher than herbal Al.

Shin et al. [8] investigated the fatigue behaviour of aluminium alloy 2024 (Al2024) strengthened with multi-walled carbon nanotubes (MWCNTs). The samples are prepared by using the use of the usage of powder metallurgy. The attrition mill have grow to be used for immoderate-electricity ball milling, the mill turned into charged with Al2024 powder, stainless steel balls, MWCNTs and $1 \mathrm{wt} \%$ stearic acid $(\mathrm{CH} 3(\mathrm{CH} 2) 16 \mathrm{CO} 2 \mathrm{H})$ as techniques control agent. The powder-to-ball weight ratio changed into $15: 1$, the mill became stirred for five $\mathrm{h}$ at $500 \mathrm{RPM}$. The ball milled powders having specific amount fraction of MWCNTs (i.E., zero, 3, 3.5, and 4 vol.\%) have been produced. The ball milled composite powders having specific composition were bloodless pressed in a preheated cylindrical mildew having pinnacle of $50 \mathrm{~mm}$ and diameter of $80 \mathrm{~mm}$ at $\sim 560 \mathrm{MPa}$ uni axially for $10 \mathrm{~min}$. The inexperienced compact was warm-pressed for consolidation. Earlier than pressing green compact have become stored in a die made from stainless steel with top of $50 \mathrm{~mm}$ and one hundred $\mathrm{mm}$. Boron nitride come to be sprayed on punch and plate to reduce friction. Then the powder modified into pressed within the mildew for $1.5 \mathrm{~h}$, at $\sim 375 \mathrm{MPa}$ and $530{ }^{\circ} \mathrm{C}$. The fatigue behaviour have emerge as placed via using using tension-compression method under load controlled situation with frequency of five $\mathrm{Hz}$ and completed stress beginning from 350 to $650 \mathrm{MPa}$. Fatigue electricity grow to be extended on addition of MWCNTs. The composite having 4 vol.\% MWCNT has staying energy over $2.5 \times 106$ cycles whilst $600 \mathrm{MPa}$ pressure modified into accomplished. Fatigue strength turn out to be evaluated the use of ratio of tensile power of tensile electricity ( $\mathrm{m}$ fee), the test gave zero.Seventy nine $\mathrm{m}$-price which shows dominating fatigue energy than Al-based totally MMCs with small quantity of MWCNTs. The advanced fatigue electricity contributes to pull-out mechanism of MWCNT which prolongs fatigue lifestyles with similarly deformation in matrix.

Deng et al.[9] investigated bloodless isostatic urgent, followed warmness extrusion technique to manufacture $1 \mathrm{wt}$. $\%$ carbon nanotubes reinforced with $2024 \mathrm{Al}$ matrix. Writer used mechanical stirring helping ultrasonic shaker in advance than ball milling for $60 \mathrm{~min}$. The mixed powders have been cold isostatic compacted at 3 hundred Mpa for 5 min. Heat extrusion with extrusion ratio $25: 1$ changed into used to prepare the pattern. It changed into decided that CNTs have been allotted homogeneously within the composite, and the interfaces bonded nicely. The experimental results showed that hardness, more youthful's modulus, yield electricity, and tensile power of the samples were stepped forward to $30.8 \%$, 23.Nine \%, sixteen.3\% and 23.Four\% in comparison to the $2024 \mathrm{Al}$ matrix respectively. The elongation of the $2024 \mathrm{Al}$ matrix and the composite pattern have become positioned to be 16.5 and $3 \%$, respectively due to a awesome bonding among the carbon nanotubes and $\mathrm{Al}$ matrix. They attributed to the superb mechanical homes of carbon nanotubes, the bridging and pulling out position of carbon nanotubes in the aluminium matrix composite.

Bunakov et al. [10] used aluminium powder and MWCNTs and people combos had been functionalized through manner of acid treatment using $\mathrm{H} 2 \mathrm{SO} 4 / \mathrm{HNO} 3$ mixture. Then the combos had been stirred to accumulate a homogenous FMWCNTs dispersion inside the Al powder. The dried suspensions had been organized which incorporate the aluminium powders with $0 \mathrm{wt} . \%$, zero. $1 \mathrm{wt} . \%, 0.25 \mathrm{wt} . \%$, 0.5 wt. $\%, 1$ wt. $\%$ FMWCNTs. Within the subsequent degree the power underneath goes spark plasma sintering in a 
vacuum at a temperature of $\operatorname{six}$ hundred ${ }^{\circ} \mathrm{C}$, underneath 50 $\mathrm{MPa}$ finished stress for $20 \mathrm{~min}$. At final cylindrical specimens of period of $\varnothing 20 \times 10 \mathrm{~mm}$ and $\varnothing 10 \times 20 \mathrm{~mm}$ had been fabricated. Writer determined an boom within the FMWCNTs quantity inside the specimen results in longer obstacles a number of the debris. In the take a look at they decided that addition of zero.1 wt. FMWCNTs can growth $30 \%$ and $16 \%$ of tensile power and micro hardness.

PM direction modified into used by Xudong et al. [11] to fabricate 2.5 wt. \% carbon nano tube strengthened with herbal aluminium.. They used following planetary ball mill parameters to fabricate the specimen, ball-to-powder ratio $=$ 10:1; diameter of the balls- $6 \mathrm{~mm}$ diameter; milling surroundings- argon environment; milling speed- $500 \mathrm{rpm}$; milling time- 30 and ninety min. Compaction stress - six hundred Mpa, sintering temperature and time $-630{ }^{\circ} \mathrm{C}$ and 1 $\mathrm{h}$ sintering environment- argon environment.; extrusion ratio and temperature $-16: 1$ and $500{ }^{\circ} \mathrm{C}$. The experimental results confirmed that the very last tensile energy of two.5 wt.\% carbon nano tube bolstered aluminium composites changed into $334 \mathrm{Mpa}$, an growth of 1.7 instances than that of unreinforced aluminium, the composite moreover showed advanced ductility property of $\sim 18 \%$ elongation to failure. Author concluded that carbon nano tube reinforcement make specific interface bonding with aluminium matrix by way of the usage of way of deeply embedment within the aluminium powder.

\section{SURRENDER}

Carbon nanotube bolstered composites are becoming significance due to their super homes however with greater traumatic conditions exists for their processing to make it a fact. This paper reviews approximately the steel matrix bolstered carbon nanotubes investigated in latest years. From this assessment future researches may additionally furthermore motive pinnacle consequences inside the fabrication of exquisite composite materials.

\section{REFERENCES}

1. M.S. Senthil Saravanan, S.P. Kumaresh Babu, ok. Sivaprasad routinely Alloyed Carbon Nanotubes (CNT) bolstered anocrystalline AA 4032: Synthesis and Characterization mag of Minerals \& substances Characterization \& Engineering, Vol. 9, No.Eleven, pp.1027-1035, 2010 jmmce.Org

2. Pérez-Bustamante, R., Estrada-Guel, I., Antúnez-Flores, W., Miki-Yoshida, M., Ferreira, P. And Martínez-Sánchez, R. (2008). Novel Al-matrix nanocomposites strengthened with multi-walled carbon nanotubes. Magazine of Alloys and Compounds, 450(1-2), pp.323-326.

3. Samuel Ratna Kumar, P., Robinson clever, D. And John Alexis, S. (2019). Corrosion behaviour of Aluminium metal Matrix bolstered with Multi-wall Carbon Nanotube.

4. Isaza Merino, C., LedezmaSillas, J., Meza, J. And Herrera Ramirez, J. (2017). Metallic matrix composites bolstered with carbon nanotubes via using an opportunity method. Mag of Alloys and Compounds, 707, pp.257-263.

5. Chen, B., Shen, J., Ye, X., Jia, L., Li, S., Umeda, J., Takahashi, M. And Kondoh, accurate enough. (2019). Period effect of carbon nanotubes on the strengthening mechanisms in metallic matrix composites.

6. Kim, W. And Yu, Y. (2019). The effect of the addition of multiwalled carbon nanotubes at the uniform distribution of TiC nanoparticles in aluminumnanocomposites.

7. Kwon, H., Lee, G., Kim, S., Lee, B., search engine optimization, W. And Leparoux, M. (2019). Mechanical houses of nanodiamond and multi-walled carbon nanotubes dual-bolstered aluminum matrix composite substances.

8. Shin, S. And Bae, D. (2019). Fatigue behavior of Al2024 alloy-matrix nanocomposites bolstered with multi-walled carbon nanotubes.

9. C.F. Deng, D.Z. Wang, X.X. Zhang, A.B. Li, Processing and houses of carbon nanotubes bolstered aluminum composites, substances technological records and Engineering A 444 (2007) 138-100 45

10. Bunakov, N., Kozlov, D., Golovanov, V., Klimov, E., Grebchuk, E., Efimov, M. And Kostishko, B. (2019). Fabrication of multi-walled carbon nanotubes-aluminum matrix composite through powder metallurgy method.

11. Xudong Yang, Enzuo Liu, Chunsheng Shi, Chunnian He , Jiajun Li , Naiqin Zhao Katsuyoshi Kondoh, Fabrication of carbon nanotube reinforced $\mathrm{Al}$ composites with properly-balanced power and ductility, mag of Alloys and Compounds 563 (2013) 216-220

\section{AUTHORS PROFILE}

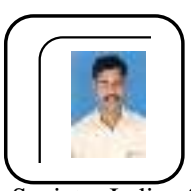

Udaya, B.E, M.Tech, cuurrently doing Ph.D in composite materials. He published papers in Material science forum, Material research express, ICETE 2018, ICAMPS 2018 conferences. Life Member of Indian Society for Technical education, Indian Welding Society, Indian Society of systems for Science and Engineering.

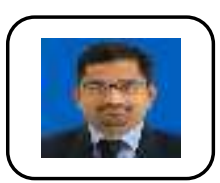

Sunil kumar shetty, BE, MTech(Design). Cuurrently pursuing his Ph.D . He has published and presented papers in conferences and Jounals. He is a Life Member of ISME, ISTE and IWS.

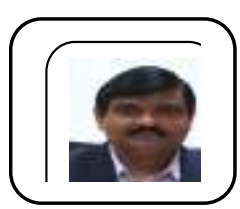

Dr. Peter Fernandes, Ph.D, M.B.A, He co-author of the papers published in Material science forum Material research express, ICETE 2018, ICAMPS 2018 conferences. Life Member of Indian Society for Technical education, Life Member of IIM Chapter. Trivandrum. 